\title{
The Agency Cost of Internal Collusion and Schumpeterian Growth *
}

\author{
David Martimort ${ }^{\dagger}$ and Thierry Verdier $\ddagger$
}

6th January 2003

\begin{abstract}
This paper analyzes the link between the internal organization of firms and the whole process of macroeconomic growth. We present a Schumpeterian growth model in which monopolies face dynamic agency costs due to the formation of vertical collusions between agents of the organization. These agency costs affect incentives to invest and the rate of innovation. However, when collusion is a self-enforcing implicit relationship, a higher growth rate shortens the time horizon of colluding agents and makes thus collusion more difficult to enforce. We analyze this two ways-mechanisms between the growth process and agency problems within the firm and show how the transaction costs of side-contracting within the firm and the growth rate of the economy are simultaneously derived.

Keywords : Bureaucratization, Schumpeterian Growth, Dynamic Collusion, Internal Organization of the Firm.

*This is an heavily revised version of our earlier paper "The Life Cycle of Monopolies, Bureaucratization and Schumpeterian Growth" (1998). We thank participants in various seminars, Aggei Semenov, and especially three referees and Mark Armstrong for their helpful comments in revising this paper.

†Université de Toulouse (IDEI-GREMAQ) and IUF, France and CEPR.

${ }^{\ddagger}$ DELTA, Paris, France and CEPR.
\end{abstract}




\section{Introduction}

Is there a link between the internal organization of the firms and the growth process? This question is a crucial one if we want to understand better the role of organizations and, more broadly of institutions, in the growth process. Until now, little effort has been devoted to this task. ${ }^{1}$

This paper is a first attempt at analyzing the interplay between the overall growth process and the agency cost within the firms involved in this process. Our motivation for this work comes from what we believe is an important tension between two assumptions made in the recent literature on Schumpeterian growth developed in Aghion and Howitt (1992, 1998) and Grossman and Helpman (1992) among others. On the one hand, these papers offer an elegant modeling of the process of creative destruction by clearly stressing out incentives for innovation and the role of monopoly profit as the engine of growth. However, because it takes a neoclassical perspective and views monopolies as black boxes, this literature completely neglects the impact of the internal organization of those firms on the growth process. Because they are monopolies, those firms operate at large scales and are thus the best candidates for the separation between ownership and control. As soon as this separation is taken seriously, agency costs within monopolies clearly matter. Organizational responses to this information gap between owners and management call for establishing supervision or monitoring technologies and for aligning incentives of agents with those of the firm's owners. A contractual perspective is needed to take into account these important features. The firm should no longer be viewed as a single entity but as a nexus of explicit and implicit contracts between owners, supervisors and managers with each of those agents pursuing their own objectives. These conflicts of interest are the source of agency costs which affect negatively the monopoly's profit. In a Schumpeterian perspective, incentives for innovation are reduced. This is the first channel by which agency cost and growth are linked.

To better describe the agency costs of large firms involved in the growth process, we follow the insights of several sociologists ${ }^{2}$ and focus on the collusion between supervisors and management as the main incentive problems of those firms. Large organizations are

\footnotetext{
${ }^{1}$ This failure is probably best explained by the modeling difficulty one encounters at describing the internal structure of the firm at a relatively detailed microeconomic level, allowing for the analysis of agency costs and organizational forms, while at the same time, integrating these considerations into a general equilibrium growth framework.

${ }^{2}$ See Dalton (1959) and Crozier (1962) among others.
} 
indeed complex networks of agents, and various cliques may form to promote their own interests rather than those of the firm's owners. Informal exchanges of favors enforce the collusive agreement among members of these cliques. For instance, and following Tirole (1986 and 1992), a supervisor may protect an agent by not revealing some information to the firm's owners and let him enjoy the corresponding information rent. In exchange, the agent may give some bribes to the supervisor out of this information rent.

The key feature of those collusive relationships is that they are implicit contracts where agents exchange favors because they expect that the continuing benefit of doing so exceeds the short-run benefit of deviating from the collusive norm and serving the principal. The stability of the environment in which the firm evolves is the fundamental glue of collusion inside organizations. ${ }^{3}$ When the process of creative destruction in a society fully exerts its clumpsering effect, vertical cliques within the firm do not form so easily. Indeed collusion becomes more difficult to enforce as the the time horizon of colluding agents is shortened by the threat of replacing the old firm they work in by new firms which offer the last vintage technology. This gives a second channel by which the outside macroeconomic environment affects agency costs within the firm.

Of course, modeling this impact of the external environment on the agency cost forces us to departing from most of the literature on collusion in organizations ${ }^{4}$ and to endogenize the efficiency of collusive exchanges between supervisors and managers. This is done by fully modeling the repeated interaction between supervisors and managers over the whole life cycle of the firm ${ }^{5}$. This endogeneity turns out to be the key to create some feed-back of growth on the internal structure of the firm.

Through this two-ways causality, incentives schemes which optimally respond to the threat of collusion within the firm depend on the growth rate of the economy. Economies with little growth are also those where incentive contracts look more like simple bureaucratic rules. Economies with a higher growth rate are instead characterized by higher powered incentives. This points at the strong complementarity between two solutions to the collusion problem. The first one is internal and consists in adjusting incentive schemes to reduce the scope for information manipulation. The second one, which is external, is to rely on the implicit threat of termination that the growth process imposes on those

\footnotetext{
${ }^{3}$ This has been noticed by several sociologists, see Pfeffer (1983) and Granovetter (1992) for a discussion on the role of the turnover of the labor force in explaining the level of inside efficiency and the degree of bureaucratization of firms.

${ }^{4}$ See Tirole (1992) for a survey.

${ }^{5}$ See Martimort (1999) for a related model.
} 
implicit relationships.

This paper belongs to a small burgeoning literature trying to link agency considerations, the internal organization of the firm and the growth process. In a model with horizontally differentiated products, Acemoglu and Zilibotti (1999) argue that the performances of competitors may provide useful information to improve incentives within a given firm and that this has an impact on growth. Aghion, Dewatripont and Rey (1999) analyze a model where the threat of bankruptcy forces conservative managers to speed up the adoption of new technologies to remain competitive on the product market. Thesmar and Thoenig (2000) endogenize the choice of organizational structures made by firms in a Schumpeterian growth model. They emphasize how these structures affect the trade-off between productivity and delay of adoption in new technologies and derive implications for wage inequality and growth.

Martimort and Verdier (2000) is the closest paper to the present one. There, we analyze a static model of collusion within the firm. Contrary to the present paper, transaction costs of side-contracting are not endogenized through the dynamics of the collusive relationships but by allowing colluding partners to invest part of their initial endowment in human capital to improve the efficiency of side-contracting. When the rate of growth is low, very few resources are used in the $\mathrm{R} \& \mathrm{D}$ sectors and human capital is relatively cheap. Investments in collusive relationships are thus easier. Collusion depresses the firm's profitability and incentives for innovation. Here, we take a less ad hoc perspective and model investments in a collusive relationship as an intangible asset. The price of the resource no longer plays a role in allocating this resource between productive and collusive activities. Agents within the firm collude because they expect that the continuing benefit of doing so exceeds the short-run gain from deviating. Since the time horizons of their relationships depends on how frequent an innovation arrives, the growth process exerts a direct disciplinary effect on collusive cliques.

Section 2 describes both the macroeconomic and the microeconomic sides of the economy. Section 3 presents a benchmark with complete information. Section 4 derives the existence and main properties of the stationary rate of growth when transaction costs of side-contracting are exogenously given. This first step is necessary to see the one sided-relationship between collusion inside the firm and growth. Section 5 goes further by deriving endogenous transaction costs in a model where the collusive behavior between agents is explicitly modeled as a repeated game. We compare there our results 
with endogenous transaction costs with those obtained with exogenous ones. After having characterized the unique equilibrium of the model, we perform several comparative statics exercices. Section 6 continues the analysis of these endogenous transaction costs and shows how they depend on the principal's ability to commit, the information structure and the process of coalition formation. Section 7 concludes by discussing several of our modeling choices and provides alleys for further research. Proofs are relegated to an Appendix.

\section{The model}

Time is discrete and indexed by $t \in\{0, \ldots+\infty\}$. The economy is populated by a continuous mass $L$ of individuals having linear preferences over the vector $y=\left\{y_{t}\right\}_{t \geq 0}$ of consumptions, namely

$$
u(y)=\sum_{t=0}^{\infty} \frac{y_{t}}{(1+r)^{t}}
$$

where $r$ is the exogenous interest rate. Each individual has one unit of labor. We denote by $w_{t}$ the corresponding wage at date $t$.

There is only one final consumption good (the numeraire) produced by competitive firms from a continuum of intermediate goods which are indexed on the unit interval. Date $t$ flow output in the final good sector is

$$
\left.y_{t}=\int_{0}^{1} y_{i t} d i \quad \text { where } y_{i t}=A_{i t} \theta_{i t} x_{i t}^{\alpha}, \alpha \in\right] 0,1[.
$$

$y_{i t}$ is the flow of input from sector $i$ used in the final sector and $x_{i t}$ is the quantity of labor used in sector $i$ to produce $y_{i t}$.

The parameter $A_{i t}$ is the "fundamental" productivity of sector $i$ at date $t$. On top of this fundamental productivity, the sector is hit by a productivity shock $\theta_{i t}$. These shocks are i.i.d. over time and sectors of the economy within the discrete distribution having support $S=\{\underline{\theta}, \bar{\theta}\}$ with respective probabilities $1-\nu$ and $\nu$. We denote by $\Delta \theta=\bar{\theta}-\underline{\theta}$ the productivity spread between a good and a bad shock.

Each intermediate good is produced by a monopolist $i$ which holds a patent of the latest generation of good $i$. We assume that this monopolist can use first-degree price discrimination to extract all surplus from the firms in the final sector using good $i$ as 
an input. This means that the monopolist $i$ can charge $A_{i t} \theta_{i t} x_{i t}^{\alpha}$ to the firms in the final sector. $^{6}$

There are as many research sectors as intermediate goods in the economy. $\mathrm{R} \& \mathrm{D}$ firms in each sector ex ante compete for the right to discover the latest generation good $i$. The arrival of innovations follows a Poisson process. With probability $\lambda E_{i t}$ where $\lambda>0$ and $E_{i t}$ is its research effort at date $t$, a $\mathrm{R} \& \mathrm{D}$ firm in sector $i$ innovates at date $t$. We assume that an $\mathrm{R} \& \mathrm{D}$ effort $E_{i t}$ can be obtained from using a quantity $\ell_{i t}$ of labor and a quantity $M_{i t}$ of final good with the following Cobb-Douglas production function :

$$
E_{i t}=\gamma^{-\gamma}(1-\gamma)^{-(1-\gamma)}\left(\frac{M_{i t}}{\bar{A}_{t}}\right)^{\gamma} \ell_{i t}^{1-\gamma}
$$

where $\bar{A}_{t}=\max _{i} A_{i t}$ is the technological frontier of society. The parameter $\gamma^{-\gamma}(1-$ $\gamma)^{-(1-\gamma)}$ is a convenient normalization. Direct optimization leads to a cost function $C\left(E_{i t}, w_{t}, \bar{A}_{t}\right)=\bar{A}_{t}^{\gamma} w_{t}^{1-\gamma} E_{i t}$ in the research sector and to a demand for labor given by $(1-\gamma) \bar{A}_{t}^{\gamma} w_{t}^{-\gamma} E_{i t}{ }^{7}$.

By innovating in sector $i$, a $\mathrm{R} \& \mathrm{D}$ firm acquires the leading-edge technology $\bar{A}_{t}$. On a stationary growth path, all $\mathrm{R} \& \mathrm{D}$ sectors invest the same amount $E$ in $\mathrm{R} \& \mathrm{D}$ and, by the Law of Large Numbers, a fraction $\lambda E$ of firms innovate at each date. Because of a positive macroeconomic externality, the technological frontier of society moves ahead by a greater amount as more firms innovate at the same time. We model this positive externality by assuming that $\bar{A}_{t}$ evolves according to the following difference equation :

$$
\bar{A}_{t+1}=\bar{A}_{t}(1+\lambda E(q-1))
$$

where $q>1$ is a measure of the macroeconomic externality due to the public good nature of knowledge. We denote by $g=\lambda E(q-1)>0$ the growth rate of the economy. On a stationary growth path, the wage $w_{t}$ grows at this rate and $\omega=\frac{w_{t}}{\bar{A}_{t}}$ is the (constant)

\footnotetext{
${ }^{6}$ In the basic model of Aghion and Howitt (1992), the monopolies use linear pricing. This adds one more allocative inefficiency without changing the basic message of the paper but with some added complexity.

${ }^{7}$ Note that the $\mathrm{R} \& \mathrm{D}$ technology exhibits constant returns to scale with respect to $E$, meaning that in equilibrium, R \& D firms will make zero profit. This has another interesting simplifying consequence which is that moral hazard in the research sector (if any) would not play any role. Suppose indeed that there is a separation between ownership and control in those firms and that the exact amount of research effort performed by the agent in a given $\mathrm{R} \& \mathrm{D}$ firm is non-verifiable. The fact that the cost function is linear in $E_{i}$ ensures that no limited liability rent needs to be left to this agent to induce him to exert the first-best level of effort. We do not claim that this irrelevance of agency costs in the R \& $\mathrm{D}$ sectors is general, but at least, it justifies our focus on agency costs in intermediate sectors.
} 
productivity-adjusted wage in the economy. We will sometimes abuse language and refer to $E$ (and not $\lambda E(q-1))$ as the growth rate of the economy.

\subsection{Inside the Firm}

Because of the symmetry among sectors, let us omit indices to make the presentation easier. Producing $y$ units of intermediate good requires $x$ units of labor in any monopoly of the intermediate sectors. We assume that the manager inside the given firm knows the realization of the productivity shocks hitting the firm at every date but that this piece of information remains unknown for the owners of the firm.

Let us denote by $U_{t+\tau}(\theta)$ the informational rent of a manager knowing the productivity shock $\theta$ at date $t+\tau$ where $t$ is the date when the firm was born. By definition, we have :

$$
U_{t+\tau}(\theta)=\bar{A}_{t} \theta x_{t+\tau}^{\alpha}(\theta)-w_{t+\tau} x_{t+\tau}(\theta)-T_{t+\tau}(\theta)
$$

where $x_{t+\tau}(\theta)$ and $T_{t+\tau}(\theta)$ are respectively the amount of labor used in production by the manager and $T_{t+\tau}(\theta)$ the dividends he pays to the owners of the firm ${ }^{8}$.

A contract between the owners of the firm (sometimes called the principal in what follows) and management (the agent) stipulates a production plan and a dividend policy $\left\{x_{t+\tau}\left(\hat{\theta}_{t+\tau}\right), T_{t+\tau}\left(\hat{\theta}_{t+\tau}\right)\right\}_{\tau \geq 0}$ as a function of the manager's report on the current shock $\hat{\theta}_{t+\tau}$ and the age of the firm $\tau$. The owners can commit to such a long-term contract.

Of course, the Revelation Principle ensures that there is no loss of generality in restricting owners to offer incentive compatible contracts such that the management finds optimal to report truthfully the productivity shock at any date.

We assume a limited commitment on the agent's side so that he can walk away from the contract at any date after having learned the productivity shock hitting the firm. This assumption is consistent with that of a free labor market. As a result, the owners cannot force a negative utility in any state and at any date. The manager must thus obtain a

\footnotetext{
${ }^{8}$ Note that the manager's rent takes into account the opportunity cost $w_{t+\tau} x_{t+\tau}(\theta)$ of using the input $x_{t+\tau}(\theta)$ elsewhere in the economy and getting the corresponding wages.
} 
positive information rent in any period for any shock realization ${ }^{9}$ :

$$
U_{t+\tau}(\theta) \geq 0, \forall \theta \in S
$$

Note that our formulation makes clear that the contract at date $t+\tau$ does not depend on the whole history of past shocks, namely $\left\{\theta_{t}, \ldots \theta_{t+\tau-1}\right\}$ which have hit the firm until that date. Roughly speaking, everything happens as if the firm were run by a sequence of short-term contracts. In fact, this is not a loss of generality. Constraint (5) can also be interpreted as a limited liability constraint stipulating that, at any date and in any state of nature, the manager must get a positive payoff. In such a context, ${ }^{10}$ Levin (2000) has shown that the optimal history dependent contract can be implemented with a sequence of short-term (non-history dependent) contracts as the ones we consider above. ${ }^{11} 12$

\section{The Complete Information Benchmark}

Let us first assume that there is no agency problem within the firm. Owners of monopolies in the intermediate sectors have complete knowledge over the productivity shocks $\theta$.

On a stationary growth path where monopolies are replaced with probabilities $\lambda E$, the discounted expected profit $V_{t}$ of a monopoly born (in any sector because of symmetry) at date $t$ is :

$$
\begin{aligned}
V_{t}= & \max _{\substack{\left\{x_{t+\tau}(\cdot) ; U_{t+\tau}(\cdot)\right\} \\
\text { subject to (4) and (5), }}} \sum_{\tau=0}^{\infty}\left(\frac{1-\lambda E}{1+r}\right)^{\tau} E_{\theta}\left(T_{t+\tau}(\theta)\right) \\
&
\end{aligned}
$$

where $E_{\theta}(\cdot)$ denotes the expectation operator with respect to the shock $\theta \cdot{ }^{13}$

\footnotetext{
${ }^{9}$ Implicit in the specification of this participation constraint is the fact that the manager finds no outside option out of the firm except not working at all if he refuses the firm's contract. This is justified if the market for managers is different from the market for labor and managers make some (unmodeled) specific investment to tailor their management skills to the firm they work with so that these skills cannot be used elsewhere in the economy.

An alternative specification would posit that the reservation level of managers is the wage rate $w_{t}$. This specification brings some analytical complexity without changing the qualitative of results of the model.

${ }^{10}$ With moral hazard instead of adverse selection and a stationary environment but it can be easily seen that the argument carries over.

${ }^{11}$ The rationale for using history-dependent contracts is that they help the principal to smooth the cost of incentive constraint between the current period and the continuation. This is useful with a decreasing marginal utility of income. With risk-neutrality and limited liability, all rewards for having revealed a good shock can be shifted in the current period without changing the cost of the incentive constraint because the marginal utility of income is the same in the current period and in the future.

${ }^{12}$ Given that, we will later on abuse language and talk about the full commitment solution to refer to the optimal contract obtained with such a sequence of short-term contracts.

${ }^{13}$ The fact that shocks are independently distributed over time allows us to omit the time index for shocks.
} 
Of course, under complete information, the manager pays out dividends up to the point where his participation constraint (5) is binding and $U_{t+\tau}(\theta)=0$ whatever $\theta$. This leads to the alternative formulation of the owners' problem :

$$
V_{t}=\max _{\left\{x_{t+\tau}(\cdot)\right\}} \sum_{\tau=0}^{\infty}\left(\frac{1-\lambda E}{1+r}\right)^{\tau} E_{\theta}\left(\bar{A}_{t} \theta x_{t+\tau}^{\alpha}(\theta)-w_{t+\tau} x_{t+\tau}(\theta)\right)
$$

The optimal demands for labor at any date $t+\tau$ are straightforwardly obtained as :

$$
x_{t+\tau}(\theta)=\left(\frac{w_{t+\tau}}{\alpha \theta \overline{A_{t}}}\right)^{\frac{1}{\alpha-1}}=\alpha^{\frac{1}{1-\alpha}} \theta^{\frac{1}{1-\alpha}} \omega^{\frac{1}{\alpha-1}}(1+g)^{\frac{\tau}{\alpha-1}} .
$$

Inserting into (6) yields the value of the discounted profit $V_{t}$ on a balanced growth path :

$$
V_{t}=\bar{A}_{t}(1-\alpha) \alpha^{\frac{\alpha}{1-\alpha}} \Theta^{\frac{1}{1-\alpha}} \omega^{\frac{-\alpha}{1-\alpha}} \frac{1}{1-\delta}
$$

where $\Theta=\left(\nu \bar{\theta}^{\frac{1}{1-\alpha}}+(1-\nu) \underline{\theta}^{\frac{1}{1-\alpha}}\right)^{1-\alpha}$ is an average measure of productivity and $\delta=$ $\left(\frac{1-\lambda E}{1+r}\right)(1+g)^{\frac{\alpha}{\alpha-1}}<1$ is the rate at which firms discount their profit.

With this equation in hands, it becomes easy to derive the arbitrage equation in the $\mathrm{R} \& \mathrm{D}$ sectors :

$$
\frac{\lambda V_{t+1}}{1+r}=\frac{\partial C}{\partial E}\left(E, w_{t}, \bar{A}_{t}\right)=\bar{A}_{t}^{\gamma} w_{t}^{1-\gamma}=\bar{A}_{t} \omega^{1-\gamma},
$$

or using (8).

$$
\lambda\left(\frac{1+g}{1+r}\right)(1-\alpha) \alpha^{\frac{\alpha}{1-\alpha}} \Theta^{\frac{1}{1-\alpha}}\left(\frac{1}{1-\delta}\right)=\omega^{\frac{1}{1-\alpha}-\gamma} .
$$

To get further insights on the shape of this curve, we will from now on assume that the interest rate $r$ and the probability of innovation $\lambda E$ are both small enough. This amounts to saying also that the length of periods is short enough so that our discrete model behaves almost as standard continuous time models of growth. ${ }^{14}$ With this approximation, we have :

$$
1-\delta \approx r+\lambda E\left(1+\frac{\alpha}{1-\alpha}(q-1)\right)
$$

\footnotetext{
${ }^{14}$ As the reader will soon figure out, the focus on a discrete time model is motivated by our desire to model the collusive relationships within the firm as a repeated game, the analysis of which is much easier with discrete time models.
} 
and (9) becomes :

$$
\omega^{\frac{1}{1-\alpha}-\gamma}=\frac{\lambda(1-\alpha) \alpha^{\frac{\alpha}{1-\alpha}} \Theta^{\frac{1}{1-\alpha}}}{r+\lambda E\left(1+\frac{\alpha}{1-\alpha}(q-1)\right)}
$$

Since $\frac{1}{1-\alpha}-\gamma>0$, the research arbitrage equation defines a strictly decreasing function $\omega_{1}(E)$ over the domain $\left[0, \frac{1}{\lambda}\right]$ where $\lambda E<1$.

To close the model, let us turn to the market clearing equation for labor. Since a firm reaches age $\tau$ with probability $\lambda E(1-\lambda E)^{\tau}$, its average production over its entire life cycle is :

$$
\begin{aligned}
X & =\sum_{\tau=0}^{\infty} \lambda E(1-\lambda E)^{\tau} E_{\theta}\left(x_{t+\tau}(\theta)\right)=\alpha^{\frac{1}{1-\alpha}} \Theta^{\frac{1}{1-\alpha}} \omega^{\frac{1}{\alpha-1}} \lambda E \sum_{\tau=0}^{\infty}(1-\lambda E)^{\tau}(1+g)^{\frac{\tau}{\alpha-1}} \\
& =\alpha^{\frac{1}{1-\alpha}} \Theta^{\frac{1}{1-\alpha}} \omega^{\frac{1}{\alpha-1}}\left(\frac{\lambda E}{1-\delta\left(\frac{1+r}{1+g}\right)}\right) .
\end{aligned}
$$

By Shephard Lemma, the demand for skilled labor of an individual firm in the research sectors is $(1-\gamma) \bar{A}_{t+\tau}^{\gamma} w_{t+\tau}^{-\gamma} E=(1-\gamma) \omega^{-\gamma} E$. The market-clearing equation becomes thus :

$$
L=(1-\gamma) \omega^{-\gamma} E+X
$$

or, to put it differently,

$$
L=(1-\gamma) \omega^{-\gamma} E+\lambda E \omega^{\frac{1}{\alpha-1}} \alpha^{\frac{1}{1-\alpha}} \Theta^{\frac{1}{1-\alpha}}\left(\frac{1}{1-\delta\left(\frac{1+r}{1+g}\right)}\right) .
$$

Inserting (9) into (12) yields the following equation which is independent of the productivity parameter $\Theta$ :

$$
\omega^{\gamma}=\frac{E}{L}\left(1-\gamma+\left(\frac{\alpha}{1-\alpha}\right)\left(\frac{1+r}{1+g}\right)\left(\frac{1-\delta}{1-\frac{\delta(1+r)}{1+g}}\right)\right)
$$

Using the approximation (10), we obtain :

$$
\omega^{\gamma}=\frac{\alpha r}{\lambda L(q-\alpha)}+\frac{E}{L}\left(1-\gamma+\frac{\alpha}{(q-\alpha)}\left(1+\frac{\alpha}{1-\alpha}(q-1)\right)\right)
$$

This equation defines a strictly increasing function $\omega_{2}(E)$ over the relevant domain $\left[0, \frac{1}{\lambda}\right]$.

Finally, gathering our previous results, we obtain : 


\section{Proposition 1}

- Assume that $\omega_{1}(0)>\omega_{2}(0)$ and $\omega_{1}\left(\frac{1}{\lambda}\right)<\omega_{2}\left(\frac{1}{\lambda}\right)$, then there exists a unique balanced growth path with a research effort $E_{0}$ and a productivity-adjusted wage $\omega_{0}$ such that: $\omega_{0}=\omega_{1}\left(E_{0}\right)=\omega_{2}\left(E_{0}\right)$.

- A decrease in $\Theta$ shifts the research arbitrage equation $\omega_{1}(E)$ down and keeps unchanged $\omega_{2}(E)$. It thus reduces the growth rate $E_{0}$ and the productivity adjusted wage $\omega_{0}$.

From now on, we will assume that the conditions of Proposition 1 which ensure existence and uniqueness of a non-trivial equilibrium are satisfied so that our analysis is meaningful.

Of significant importance for what follows is our result that the growth rate of the economy decreases as the productivity index $\Theta$ is deflated. In fact, as $\Theta$ decreases, the research arbitrage equation is shifted down because $R \& D$ firms have less incentives to innovate as the profit in the intermediate sectors diminishes ( $E_{0}$ decreases). These depressed incentives reduce the demand for skilled labor in the research sectors and make it cheaper ( $\omega_{0}$ decreases).

\section{Agency Cost without Supervision}

Let us now consider the case where the manager is privately informed on the productivity shock. On top of the participation constraints (5), we must add the following incentive compatibility constraints to induce the manager to report the true state of nature to owners at each given date

$$
U_{t+\tau}(\theta) \geq \bar{A}_{t} \theta x_{t+\tau}^{\alpha}\left(\theta^{\prime}\right)-w_{t+\tau} x_{t+\tau}^{\alpha}\left(\theta^{\prime}\right)-T_{t+\tau}\left(\theta^{\prime}\right), \forall\left(\theta, \theta^{\prime}\right) \in S^{2}
$$

It is well known from incentive theory ${ }^{15}$ that the relevant (binding) incentive constraint is that of a high productivity agent willing to mimic a low productivity one to save on the dividends given back to the owners. This constraint rewrites as :

$$
U_{t+\tau}(\bar{\theta}) \geq U_{t+\tau}(\underline{\theta})+\bar{A}_{t} \Delta \theta x_{t+\tau}^{\alpha}(\underline{\theta}) .
$$

\footnotetext{
${ }^{15}$ See Laffont and Martimort (2002) for instance.
} 
Since $x_{t+\tau}^{\alpha}(\underline{\theta}) \geq 0,(16)$ implies that the only relevant participation constraint is :

$$
U_{t+\tau}(\underline{\theta}) \geq 0
$$

Intuitively, the possibility of information manipulations forces owners to leave more rent to the manager than what they have to do under complete information. This rent is an extra cost for owners who modify the production plans of the firm to reduce the scope for information manipulation and thus these information rents. Taking into account incentive constraints, we can now rewrite the intertemporal profit of the monopolist on a balanced growth path as :

$$
\begin{gathered}
V_{t}=\max _{\left\{x_{t+\tau}(\cdot), U_{t+\tau}(\cdot)\right\}} \sum_{\tau=0}^{\infty}\left(\frac{1-\lambda E}{1+r}\right)^{\tau}\left\{E_{\theta}\left(\bar{A}_{t} \theta x_{t+\tau}^{\alpha}(\theta)-w_{t+\tau} x_{t+\tau}(\theta)-U_{t+\tau}(\theta)\right)\right\} \\
\text { subject to (16) and (17). }
\end{gathered}
$$

Both constraints are obviously binding at the optimum. The high-productivity manager gets a positive rent $U_{t+\tau}(\bar{\theta})=\bar{A}_{t} \Delta \theta x_{t+\tau}^{\alpha}(\underline{\theta})$ and is paid more than his opportunity wage. Instead, the low-productivity manager gets zero rent, i.e., he is exactly compensated for his opportunity cost of not working elsewhere in the economy.

Replacing these expressions into the maximand of the problem above, everything happens thus as if the true productivity $\underline{\theta}$ of the low-productivity firm was replaced by a virtual productivity which is lower, namely :

$$
\underline{\tilde{\theta}}=\underline{\theta}-\frac{\nu}{1-\nu} \Delta \theta<\underline{\theta} .
$$

Instead, the virtual productivity of a high productivity firm remains unchanged and is still equal to its true value. ${ }^{16}$

The optimal production plan of the firm is modified accordingly. There is no reason to distort the production of the high productivity management and still $x_{t+\tau}(\bar{\theta})=$ $\alpha^{\frac{1}{1-\alpha}} \bar{\theta}^{\frac{1}{1-\alpha}} \omega^{\frac{1}{\alpha-1}}(1+g)^{\frac{\tau}{\alpha-1}}$ just like under complete information. Instead, to reduce the costly information rent, the production is downward distorted in state $\underline{\theta}$ and it becomes :

$$
x_{t+\tau}(\underline{\tilde{\theta}})=\alpha^{\frac{1}{1-\alpha}}(\underline{\tilde{\theta}})^{\frac{1}{1-\alpha}} \omega^{\frac{1}{\alpha-1}}(1+g)^{\frac{\tau}{\alpha-1}} .
$$

Of course, the same research arbitrage and market clearing equations as under complete information hold if we take care of replacing the productivity index $\Theta$ by a virtual

\footnotetext{
${ }^{16}$ To avoid corner solutions, we will assume that $\underline{\tilde{\theta}}$ remains always positive which puts an upper bound on the spread of uncertainty on the firm's productivity shock.
} 
index which is strictly smaller, namely:

$$
\tilde{\Theta}=\left(\nu \bar{\theta}^{\frac{1}{1-\alpha}}+(1-\nu) \underline{\tilde{\theta}}^{\frac{1}{1-\alpha}}\right)^{1-\alpha}<\Theta .
$$

This modification of the productivity index shifts down the research equation (9), keeping unchanged (13). As a result, we immediately obtain :

Proposition 2 Asymmetric information within intermediate sectors :

- reduces the productivity adjusted wage, $\omega^{A I}<\omega_{0}$;

- reduces the growth rate, $E^{A I}<E_{0}$.

\section{Supervision and Collusion}

To fill the information gap with management, owners may hire a supervisor whose only task is to gather information on the productivity shock hitting the firm. ${ }^{17}$ To model supervision as simply as possible, we assume that the supervisor can perfectly observe the shock $\theta$. Moreover, his monitoring technology makes this piece of information verifiable only when $\underline{\theta}$ realizes. When $\bar{\theta}$ realizes, the supervisor can still manipulate information and pretend that the firm is in state $\underline{\theta}$. In other words, only "bad news" on the firm's productivity can be given hard evidence. ${ }^{18}$

To simplify the presentation, we also assume that the owners no longer directly communicate with the agent. In fact, it is easy to see that such a communication is useless as soon as the supervisor and the agent collude against the principal (as we will assume thereafter) since they can then coordinate their individual reports on the state of nature that they commonly observe to the principal. ${ }^{19}$

\footnotetext{
${ }^{17}$ See Tirole (1986 and 1992) for earlier models of supervision within the firm.

${ }^{18}$ This information structure shows that the role of the supervisor is to reduce the set of incentive compatibility constraints faced by the principal since the supervisor cannot report $\bar{\theta}$ when $\underline{\theta}$ has realized. As we will see below, this information structure still leaves some scope for information manipulations. Alternatively, we could, as in Tirole (1986)'s seminal paper on collusion, model the supervisor as having access to an imperfect signal $\sigma$ of the productivity which is hard information, i.e., can be concealed but not manipulated. For instance, $\sigma$ could be $\theta$ with probability $\varepsilon$ and uninformative otherwise. Such an information structure maintains more symmetry in the different states of nature than that we have chosen in the text. However, it leads exactly to the same result than what we obtain below with the added complexity of increasing the number of states of nature from 2 to 4 . This can be seen by comparing the results we obtain thereafter with those in the earlier version of this work. Our modeling choice is thus dictated by simplicity and by our strong concern of embedding the simplest model of collusion into a general equilibrium model.

${ }^{19}$ For more general results along these lines, see Faure-Grimaud, Laffont and Martimort (2001).
} 
Finally, note that the only task of the supervisor is to gather information and he is not directly involved in the production process. Given that, the supervisor is only interested in the wage $s_{t+\tau}(\theta)$ he receives in both states of nature.

To keep symmetry between the supervisor and the agent, we also assume that the supervisor can walk away from the firm at any time once he has observed the state of nature. His wage has to be greater than zero in any state of nature to remain in the firm. ${ }^{20}$

In this context, a feasible contract is a vector $\left\{x_{t+\tau}\left(\hat{\theta}_{t+\tau}\right), s_{t+\tau}\left(\hat{\theta}_{t+\tau}\right), T_{t+\tau}\left(\hat{\theta}_{t+\tau}\right)\right\}_{\tau \geq 0}$ stipulating respectively the labor demands and transfers to both supervisor and the management as a function of the supervisor's report $\hat{\theta}$. Of course, in equilibrium, the supervisor reports the truth to the principal. Once $\theta$ is learned by the principal, the latter fixes $T_{t+\tau}(\theta)$ to extract all the management's rent, namely

$$
T_{t+\tau}(\theta)=\bar{A}_{t} \theta x_{t+\tau}^{\alpha}(\theta)-w_{t+\tau} x_{t+\tau}
$$

Had the supervisor been honest, a flat wage $s_{t+\tau}(\theta)=0$ for all $\theta$ would be enough to make him reveal the true state of nature to the firm's owners. The optimal contract would request the first-best outputs and the organization would not suffer from any agency cost.

Instead, following the important observation made by sociologists, ${ }^{21}$ we assume that the supervisor pursues other interests than those of the owners of the firm. He and the manager collude to protect the information rent that the latter can get if the supervisor hides evidence in favor of the agent.

There is a stake of collusion in state $\bar{\theta}$ because the management's rent is non-negative in this state. By reporting $\underline{\theta}$ instead of $\bar{\theta}$ when $\bar{\theta}$ realizes at date $t+\tau$, the supervisor can indeed let the high-productivity management benefit from the positive $\operatorname{rent} U_{t+\tau}(\bar{\theta})=$ $\bar{A}_{t} \Delta \theta x_{t+\tau}^{\alpha}(\underline{\theta}) \cdot{ }^{22}$ Of course, the corruptible supervisor is ready to do that if he receives a bribe which is worth this whole amount, assuming that he has all bargaining power in the collusion.

\footnotetext{
${ }^{20}$ As for managers, we assume that each firm needs a fixed quantity of supervisory activity, typically one unit, that there is as many potential supervisors as firms in the intermediate sectors and that this activity does not use any labor, or at least another sort than that used for production. This ensures that the only outside opportunity of a supervisor is not to work at all and get thereby zero.

${ }^{21}$ See, among others, Crozier (1962) and Dalton (1954).

${ }^{22}$ Suppose that the information structure is the "reverse" to that assumed so far, i.e., the supervisor can only provide hard evidence on $\bar{\theta}$ but not on $\underline{\theta}$. In this case, there would be no stake of collusion because the $\underline{\theta}$ obtains zero rent both when the supervisor reports the agent's type and when he does not. Collusion matters only if the supervisor knows a piece of manipulable information which gives some rent to the management.
} 
Let us suppose that the collusive side-contract between the supervisor and the manager can be perfectly enforced but that there exists a dead-weight loss of side-contracting so that the supervisor's private benefit from being bribed an amount $b$ is only equal to $k b$ where $0<k<1$. We will refer sometimes to $1-k$ as the (marginal) transaction costs of side-contracting. For the time being, we will assume that this cost is exogenously given.

To induce revelation of information by the corruptible supervisor, the following coalitionincentive compatibility constraint must be satisfied :

$$
s_{t+\tau}(\bar{\theta}) \geq k \bar{A}_{t} \Delta \theta x_{t+\tau}^{\alpha}(\underline{\theta}) .
$$

Also, the supervisor must receive a positive wage at any given date so that the following constraint holds $:^{23}$

$$
s_{t+\tau}(\underline{\theta}) \geq 0 \text {. }
$$

The owner's problem becomes thus :

$$
V_{t}=\max _{\left\{x_{t+\tau}(\cdot), U_{t+\tau}(\cdot), s_{t+\tau}(\cdot)\right\}} \sum_{\tau=0}^{\infty}\left(\frac{1-\lambda E}{1+r}\right)^{\tau}\left\{E_{\theta}\left(\bar{A}_{t} \theta x_{t+\tau}^{\alpha}(\theta)-w_{t+\tau} x_{t+\tau}(\theta)-s_{t+\tau}(\theta)\right)\right\}
$$

Of course, both constraints are binding at the optimum. The supervisor must be rewarded $\left(s_{t+\tau}(\theta)>0\right)$ to induce him not to collude in state $\bar{\theta}$. Comparing (20) and (16) when binding, it is straightforward to observe that the only difference with Section 4 comes now from the lower weight $k$ (less than one) put on the cost of information rent in the owner's objective function. Supervision is useful in bridging the informational gap even with the threat of collusion.

Everything happens now as if the virtual productivity becomes an explicit function of the efficiency of collusion

$$
\underline{\tilde{\theta}}(k)=\underline{\theta}-\frac{\nu}{1-\nu} k \Delta \theta<\underline{\theta} .
$$

Of course, the productivity index $\tilde{\Theta}$ must be transformed into $\tilde{\Theta}(k)$ accordingly.

Note that as $k$ increases, preventing collusion becomes more costly for the owners who have to reduce more significantly the output and thus the rent over which the supervisor has discretion. The shift towards low-powered incentives within the firm can be

\footnotetext{
${ }^{23}$ Clearly, (20) implies that the supervisor obtains a non-negative wage when $\bar{\theta}$ realizes, $s_{t+\tau}(\bar{\theta})>0$ as long as the production remains positive.
} 
interpreted as a move towards more bureaucratic rules which leave little discretion to the intermediate layer of the hierarchy.

Again, modulo the slight modification of $\tilde{\Theta}(k)$ seen above, the previous analysis goes through. For ease of notations, we will nevertheless make the dependency of the researcharbitrage equation on $k$ explicit and refer to it as $\omega_{1}(E, k)$. We then have:

Proposition 3 Assume that $\omega_{1}(0, k)>\omega_{2}(0)$ and $\omega_{1}\left(\frac{1}{\lambda}, k\right)<\omega_{2}\left(\frac{1}{\lambda}\right)$, then, there exists a unique stationary equilibrium of the economy $(\omega(k), E(k))$ with exogenous transaction costs. As the efficiency of collusion $k$ increases :

- The productivity-adjusted wage $\omega(k)$ decreases,

- The growth rate of the economy $E(k)$ decreases.

As the efficiency of side-contracting increases, the virtual productivity index decreases and the incentives for innovation in the $\mathrm{R} \& \mathrm{D}$ sectors diminish, reducing thereby growth in the economy.

The parameter $k$ allows us to describe a whole set of possible growth paths for an economy depending on how easy it is to enforce the implicit collusive agreements between members of the firm. This parameter is clearly affected by various cultural parameters, like the more or less important respect of a "word of honor" between agents involved in a collusive relationship, whether the "corporate culture" of the firm favors or not shirking activities or the peer pressure that an agent can feel when deviating away from the collusive norm.

The simple model we have proposed above already shows how sociological considerations affect the growth process of the economy. Organizations where collusive relationships between vertical layers develop more easily will be more of a brake to the growth process.

In the next section, we are interested in the reverse causality : how the growth process affects the norms of social behavior within the firm.

Remark: Implicit in the above formulation is the fact that the enforceable collusive side-contracts run only for a single period. It should be clear that, keeping transaction costs constant, considering long-term side-contracts would not change the results. Indeed, a long-term side-contract running over the whole life of the firm would instead consist of, first, a commitment of the supervisor for manipulating the reports made to the owners at any single date when $\bar{\theta}$ realizes and, second, a commitment of the agent for bribing the 
supervisor at any such date. The coalition incentive compatibility constraints for such behavior would be:

$$
\sum_{\tau=0}^{\infty}\left(\frac{1-\lambda E}{1+r}\right)^{\tau} s_{t+\tau}(\bar{\theta}) \geq k\left(\sum_{\tau=0}^{\infty}\left(\frac{1-\lambda E}{1+r}\right)^{\tau} \bar{A}_{t} \Delta \theta x_{t+\tau}^{\alpha}(\underline{\theta})\right),
$$

where $\frac{1-\lambda E}{1+r}$ is the true discount factor faced by the supervisor living in a firm which may disappear with probability $\lambda E$ at each date.

Clearly (23) is implied by (21) and it can easily be check that the optimal contracts facing a short-term and a long-term enforceable collusions are the same as long as longterm enforceable side-contracts correspond to the same transaction costs than short-term ones. $^{24}$

\section{Endogenous Transaction Costs}

Let us now envision the relationship between the supervisor and the manager as an implicit and self-enforcing contract. This is then the expectation of those agents over the benefits of continuing their collusive relationship in the future which motivates the exchange of favors at any given date.

For a given firm born at date $t$, let us fix the whole path of labor demands $\{x(\cdot)\}_{\tau \geq 0}$ and the corresponding whole path of rents $\left.\left\{U_{t+\tau}(\cdot)\right\}_{\tau \geq 0}\right)$. This contract defines a multistage game $\Gamma_{t}$ played by the supervisor and the agent (the manager). At each date $t+\tau$, the space of supervisor's strategies is the set of reports $\hat{\theta} \in S=\{\underline{\theta}, \bar{\theta}\}$ that he can make when he observes $\theta=\bar{\theta}{ }^{25}$ The space of the agent's strategies available at date $t+\tau$ is the set of possible bribes $b_{t+\tau}$ that he can make when a good shock $\bar{\theta}$ hits, i.e., the bounded interval $\left[0, U_{t+\tau}(\bar{\theta})\right]$.

The timing of each stage (at date $\tau$ ) of $\Gamma_{t}$ is the following. First the supervisor reports ; second, the agent bribes the supervisor. There is an obvious equilibrium of $\Gamma_{t}$ which consists of an infinite repetition of the unique subgame perfect equilibrium of the stage game. In this equilibrium, the supervisor reports always $\bar{\theta}$ truthfully to the

\footnotetext{
${ }^{24} \mathrm{~A}$ generalization of this framework would thus be to have the collusive agents invest part of their human capital into the technology of side-contracting to make long-term side-contracts more efficient than short-term ones. For stationary grand-contracts offered by the principal, the coalition-incentive compatibility constraint (23) can be transformed as a static coalition-incentive constraint linking the stream of supervisor's wages and the stream of outputs of the firm at the start of its life. With respect to what follows, this amounts to assuming that agents can choose, at a cost, the parameter $k$ in an essentially static model. These issues have been analyzed in Martimort and Verdier (2000).

${ }^{25}$ Remember that the supervisor cannot manipulate information when he observes $\theta=\underline{\theta}$.
} 
owners if $\bar{\theta}$ has realized; the agent gets zero rent and does not bribe. This is obviously an equilibrium since, by deviating, the supervisor leaves some rent to the agent but gets no bribe from the latter. Of course, in this equilibrium, they both get their respective minmax payoffs.

There exists of course other subgame-perfect equilibria of $\Gamma_{t}$ which are more collusive. The most collusive one is obtained when the supervisor hides the agent's type in each period and the latter bribes accordingly.

Consider the following trigger strategies supporting this kind of collusion in $\Gamma_{t}$ :

Supervisor : He reports $\hat{\theta}_{t+\tau}=\underline{\theta}$ to owners when $\bar{\theta}$ has been observed at date $\tau$ as long as the agent has given a bribe $b_{t+\tau^{\prime}}=U_{t+\tau^{\prime}}(\bar{\theta})-\varepsilon$ at all previous dates $t+\tau^{\prime}$ for $\tau^{\prime}<\tau$. If there is a single date $t+\tau_{0}$ (where $\tau_{0} \geq 0$ ) at which the high-productivity manager does not give a positive bribe $b_{t+\tau}=U_{t+\tau}(\bar{\theta})-\varepsilon$ (for some $\varepsilon$ small enough), then the supervisor reports $\hat{\theta}_{t+\tau}=\bar{\theta}$ when $\bar{\theta}$ is observed at all dates $t+\tau>t+\tau_{0}$.

Agent : He bribes the supervisor an amount $b_{t+\tau}=U_{t+\tau}(\bar{\theta})-\varepsilon$ at date $t+\tau$ as long as the supervisor has always reported $\hat{\theta}_{t+\tau^{\prime}}=\underline{\theta}$ when $\bar{\theta}$ has realized for all $\tau^{\prime} \leq \tau$. If there is a single date $t+\tau_{0}$ at which the supervisor does report $\hat{\theta}_{t+\tau_{0}}=\bar{\theta}$ when $\bar{\theta}$ has realized, then the agent stops giving any bribe to the supervisor at all future dates $t+\tau \geq t+\tau_{0}$.

Let us check that those strategies form a subgame-perfect equilibrium of $\Gamma_{t}$. For the supervisor to behave in a collusive way, we must have :

$\sum_{\tau=0}^{\infty}\left(\frac{1-\lambda E}{1+r}\right)^{\tau}\left(\nu s_{t+\tau}(\bar{\theta})+(1-\nu) s_{t+\tau}(\underline{\theta})\right) \leq \sum_{\tau=0}^{\infty}\left(\frac{1-\lambda E}{1+r}\right)^{\tau}\left(\nu b_{t+\tau}+(1-\nu) s_{t+\tau}(\underline{\theta})\right)$

where the left-hand side represents the benefit from deviating and reporting truthfully from date $t$ on and the right-hand side the benefits of colluding.

Of course, there is no need to pay the supervisor when he reports $\underline{\theta}$ since there is no stake of collusion in this state of nature and we have $s_{t+\tau}(\underline{\theta})=0$. We finally get :

$$
\sum_{\tau=0}^{\infty}\left(\frac{1-\lambda E}{1+r}\right)^{\tau} s_{t+\tau}(\bar{\theta}) \leq \sum_{\tau=0}^{\infty}\left(\frac{1-\lambda E}{1+r}\right)^{\tau} b_{t+\tau}
$$

For the agent to behave in a collusive way, we must instead have :

$$
U_{t}(\bar{\theta}) \leq \sum_{\tau=0}^{\infty}\left(\frac{1-\lambda E}{1+r}\right)^{\tau}\left(U_{t+\tau}(\bar{\theta})-b_{t+\tau}\right)
$$


where the left-hand side represents the short-run gain from not bribing the supervisor at date $t$.

A necessary condition for the profile of bribes $\left\{b_{t+\tau}\right\}_{\tau \geq 0}$ to be sustainable is that both (24) and (25) hold simultaneously. In this case, neither the supervisor nor the manager will deviate from their collusive agreement at date $t .^{26}$

Owners break the collusion by offering an incentive scheme to both the supervisor and the management which makes impossible to realize simultaneously (24) and (25). The corresponding coalition-incentive compatibility constraint writes thus as :

$$
\left.\sum_{\tau=0}^{\infty}\left(\frac{1-\lambda E}{1+r}\right)^{\tau} s_{t+\tau}(\bar{\theta}) \geq \sum_{\tau=1}^{\infty}\left(\frac{1-\lambda E}{1+r}\right)^{\tau} U_{t+\tau}(\bar{\theta})\right) .
$$

This constraint which links the intertemporal wage profile of the supervisor to the firm's output takes a much simpler form in the case of contracts specifying a constant growth rate for outputs and wages. Typically, let us write $s_{t+\tau}(\bar{\theta})=s_{t}(\bar{\theta})(1+g)^{\frac{\tau \alpha}{\alpha-1}}$ and $x_{t+\tau}(\theta)=x_{t}(\theta)(1+g)^{\frac{\tau}{\alpha-1}}$ for all $\theta$ in $S$ and any date $t+\tau$ where $\tau \geq 0$. Inequality (26) takes the stationary simpler form :

$$
s_{t}(\bar{\theta}) \geq \delta(E) U_{t}(\bar{\theta})
$$

where $\delta(E)=\left(\frac{1-\lambda E}{1+r}\right)(1+g)^{\frac{\alpha}{\alpha-1}}$ and $U_{t}(\bar{\theta})=\bar{A}_{t} \Delta \theta x_{t}^{\alpha}(\underline{\theta})$. Note again that, when $r$ and $\lambda$ are both small enough, $\delta(E)$ can be approximated by $(10)$.

The restriction to simple stationary contracts made above reduces drastically the complexity of the coalition-incentive compatibility constraint which becomes now a simple constraint linking the initial supervisor's wage and the manager's rent when the firm is born. Given that wages and outputs follow a stationary growth path, this coalitionincentive compatibility constraint also links the supervisor's wage and the manager's rent all along the life cycle of the firm. This is particularly clear when (27) is binding. Indeed, (27) binding implies also that (26) holds at any date $t+\tau$ with an efficiency of side-contracting $k=\delta(E)$ which now depends on the growth rate of the economy. We thus have:

$$
s_{t+\tau}(\bar{\theta})=\delta(E) U_{t+\tau}(\bar{\theta}) .
$$

The fact that $\delta(E)<1$ shows immediately that it is always better to use the supervisor than not using it. It is worth noticing that this implies also that there is no gain to let

\footnotetext{
${ }^{26}$ For the moment, we postpone the discussion of the scope for deviations from the collusive agreement at any date $t+\tau(\tau>1)$.
} 
collusion occur in equilibrium. Indeed, in this case, the principal would have to pay a greater amount, namely $U_{t+\tau}(\bar{\theta})$, to make the agent reveal information. A CollusionProofness Principle holds thus in our context.

The restriction to stationary contracts made above may entail a loss of generality. To our defense, first note that nothing is so far known on the design of the optimal history dependent contract in front of a self-enforcing collusion. Looking in first approximation to the case of stationary contracts seems to us a legitimate exercice since those contracts are optimal when no collusion takes place. ${ }^{27}$ Second, for a stationary contract the coalitionincentive compatibility constraint (27) implies that all subgames of $\Gamma_{t}$ are equivalent in terms of the supervisor and the manager's incentives to deviate from the collusive agreement. Henceforth, the owners do not find more valuable to break the self-enforcing collusion starting at date $t$ by inducing a deviation in a subgame of $\Gamma_{t}$ than to break it at date $t$ itself. $^{28}$ This seems to us as an attractive property of stationary contracts. Finally, constraint (27) also ensures that the multistage game $\Gamma_{t+\tau}$ defined by the continuation of the contract from date $t+\tau$ on is immune to any collusive equilibrium. This simply means that satisfying (27) prevents collusion starting at any date in the future.

One major result of the analysis made above is that the transaction costs of sidecontracting depend now on the growth rate. This offers a quite simple channel by which the economy at large affects incentive schemes within the firm. As the growth rate of the economy increases, $E$ decreases and the efficiency of side-contracting decreases also $\left(\delta^{\prime}(E)<0\right)$. More growth shortens the horizon of agents involved in implicit relationships within the firm and this relaxes the owners' problem. Our model predicts therefore a positive correlation between growth and the power of incentives within the firm. Less bureaucratic organizations emerge as the growth process exerts a greater threat of termination on collusive relationships within the firm.

Let us now turn to the equilibrium consequence of this endogenization of transaction costs. Of course, equation (14) remains unchanged since it does not depend on the productivity index and collusion affects only this index which becomes an implicit function

\footnotetext{
${ }^{27}$ In a recent paper, Che and Yoo (2001) analyze optimal long-term contracting when agents may collude implicitly and also restrict themselves to stationary contracts which, in their context where the economy as a whole does not change, are constant.

${ }^{28}$ Otherwise, we could have the unpalatable conclusion that self-enforcing collusion is costless to owners if they can fully commit to history dependent contract. It is enough for that to commit to a large reward (but bounded) in the far future in case the supervisor tells $\bar{\theta}$ at this date. By an unraveling argument, this breaks collusion in all periods before and, by doing so, the owners approximate the first-best profit.
} 
of the growth rate. We have :

$$
\tilde{\Theta}(E)=\left(\nu \bar{\theta}^{\frac{1}{1-\alpha}}+(1-\nu) \tilde{\tilde{\theta}}(E)^{\frac{1}{1-\alpha}}\right)^{1-\alpha}
$$

where $\underline{\tilde{\theta}}(E)=\underline{\theta}-\frac{\nu}{1-\nu} \delta(E) \Delta \theta$ is the virtual productivity with endogenous transaction costs.

Instead, the research arbitrage equation (11) is changed accordingly. Two opposite effects are at work on this research-arbitrage equation. As before a higher growth rate $E$ reduces the expected life of monopolists in the research sectors and thus depresses incentives in the R \& D sectors (denominator of (11)). On the other hand, more growth reduces agency costs by shortening also the expected life of implicit relationships within the firm. The productivity index $\tilde{\Theta}(E)$ increases with $E$ (numerator of $(11)$ ). It is a priori unclear which of these effects dominates and whether $\omega_{1}(E)$ remains always decreasing. We can nevertheless prove the following :

Proposition 4 The research arbitrage equation (11) defines a strictly decreasing function of $E, \tilde{\omega}_{1}(E)$. Assume that $\tilde{\omega}_{1}(0)>\omega_{2}(0)$ and that $\tilde{\omega}_{1}\left(\frac{1}{\lambda}\right)<\omega_{2}\left(\frac{1}{\lambda}\right)$, then there exists a unique stationary equilibrium $\left(\omega^{*}, E^{*}\right)$ with $\omega^{*}>\omega\left(\frac{1}{1+r}\right)$ and $E^{*}>E\left(\frac{1}{1+r}\right)$.

If there was no innovation in society, self-enforceable collusive exchanges would be only limited by the fact that collusive agents discount the future, i.e., by the interest rate of the economy. The factor $\frac{1}{1+r}$ represents thus an upper bound on the efficiency of side-contracting. When $k=\frac{1}{1+r}$ is chosen in a model with exogenous transaction costs, the productivity index is minimal and the growth rate is at its lowest level. Starting from this simple benchmark, and endogenizing now the transaction costs, a higher growth rate decreases the efficiency of side-contracting, increases the productivity index, and shifts upwards the research-arbitrage equation. The equilibrium growth rate and the productivity-adjusted wage are thus greater.

It is worth stressing also that the increase in the productivity index as $E$ gets larger is not enough to make $\tilde{\omega}_{1}(\cdot)$ increase over some range with the possibility of generating multiple steady states in the economy. Nevertheless, note that our model generates some positive externality due to agency costs : more growth in the economy reduces agency costs within each firm, increases profit, which in turn generates better incentives in the $\mathrm{R} \& \mathrm{D}$ sectors and triggers more growth.

This positive externality leads to a multiplier effect : the growth rate of the economy may be more sensitive to variations of exogenous parameters in the model with endogenous 
transaction costs than with exogenous ones. To see this simple point, let us denote by $Y$ the vector of exogenous parameters to the model : $Y=(\lambda, \alpha, q, L)$ and let us make explicit the dependency of $\tilde{\omega}_{1}(\cdot), \omega_{2}(\cdot)$ and $\delta(\cdot)$ on this vector.

With endogenous transaction costs, the unique steady state $E^{*}(Y)$ is such that :

$$
\tilde{\omega}_{1}\left(E^{*}(Y), Y\right)=\omega_{2}\left(E^{*}(Y), Y\right) \text { for all } Y \text {. }
$$

Of course, $E^{*}(Y)$ is also the equilibrium growth rate in a model with exogenous transaction costs in the special case where $k=\delta\left(E^{*}(Y)\right)$, namely :

$$
\omega_{1}\left(E^{*}(Y), k, Y\right)=\omega_{2}\left(E^{*}(Y), Y\right) .
$$

As the set of exogenous parameter varies, keeping now $k$ fixed, one (implicitly) describes the whole equilibrium correspondence $E(k, Y)$ such that

$$
\omega_{1}(E(k, Y), k, Y)=\omega_{2}(E(k, Y), Y) \text { for all } Y \text {. }
$$

Using the implicit function theorem, $E(k, Y)$ is locally unique and we have :

$$
\frac{\partial E}{\partial Y}(k, Y)=\frac{\frac{\partial \omega_{2}}{\partial Y}-\frac{\partial \omega_{1}}{\partial Y}}{\frac{\partial \omega_{1}}{\partial E}-\frac{\partial \omega_{2}}{\partial E}}
$$

Instead, taking into account that $E^{*}(Y)=E\left(\delta\left(E^{*}(Y), Y\right), Y\right)$, we have

$$
E^{*^{\prime}}(Y)=\frac{\frac{\partial \omega_{2}}{\partial Y}-\frac{\partial \omega_{1}}{\partial Y}-\frac{\partial \omega_{1}}{\partial k} \frac{\partial \delta}{\partial Y}}{\frac{\partial \omega_{1}}{\partial E}+\frac{\partial \omega_{1}}{\partial k} \frac{\partial \delta}{\partial E}-\frac{\partial \omega_{2}}{\partial E}} .
$$

We can finally write the partial derivative of the equilibrium growth rate with endogenous transaction costs as :

$$
E^{*^{\prime}}(Y)=\left(\frac{1-\frac{\frac{\partial \omega_{1}}{\partial k} \frac{\partial \delta}{\partial Y}}{\frac{\partial \omega_{2}}{\partial Y}-\frac{\partial \omega_{1}}{\partial Y}}}{1+\frac{\frac{\partial \omega_{1}}{\partial k} \frac{\partial \delta}{\partial E}}{\frac{\partial \omega_{1}}{\partial E}-\frac{\partial \omega_{2}}{\partial E}}}\right) \frac{\partial E}{\partial Y}\left(\delta\left(E^{*}(Y), Y\right), Y\right)
$$

Since $\frac{\partial \omega_{1}}{\partial E}<0<\frac{\partial \omega_{2}}{\partial E}, \frac{\partial \delta}{\partial E}<0$ and $\frac{\partial \omega_{1}}{\partial k}<0$ (lower transaction costs shift the research equation down), the denominator of the bracketed term is lower than one. Hence, a 
multiplier effect takes place when we have also $\frac{\partial \delta}{\partial Y}\left(\frac{\partial \omega_{2}}{\partial Y}-\frac{\partial \omega_{1}}{\partial Y}\right)>0$. In this case, the equilibrium growth rate is more sensitive to exogenous changes in parameters now that agency costs are linked to the macroeconomic environment. We use this fact to get the following corollary.

Corollary 1 Assume that $\lambda$ and $r$ are small enough so that the approximations (10) and (11) hold, then an increase in $\lambda$ (resp. an increase L) increases more the growth rate when agency costs are endogenous than when they are not. The comparative statics is ambiguous for an increase in $r$.

It is clear that a better $\mathrm{R} \& \mathrm{D}$ technology ( $\lambda$ greater) increases the incentives of $\mathrm{R}$ \& D firms by making R\&D more successful ; the dominant effect is that $\omega_{1}(\cdot)$ is shifted up even if those firms realize that their expected life will be shorter and profits will be more discounted as innovations are also more likely in the future. At the same time, this shorter expected life of the intermediate sectors shortens also implicit collusion and reduces agency costs. This effect exacerbates growth even further. An immediate consequence of this result is that general purpose technologies which may improve the whole process of research are associated with radical changes in organizational forms which tend to be less bureaucratized as those technologies are adopted.

The comparative statics with respect to $L$ is also easy to obtain. The scale of the economy does not affect agency costs directly, $\delta(\cdot)$ is indeed independent of $L$. However, increasing $L$, (may be by opening frontiers between segmented markets for skilled labor) increases the growth rate. In turn, this reduces agency costs which improves further the incentives in the R \& D sectors, fostering thereby growth.

Unambiguous comparative statics are no longer obtained when we vary the interest rate. Increasing $r$ decreases the discounted profits that an innovator expects from holding a patent. This reduces incentives in the $\mathrm{R} \& \mathrm{D}$ sectors. At the same time, increasing $r$ increases transaction costs of side-contracting and reduces agency costs, fostering thereby incentives in the $\mathrm{R} \& \mathrm{D}$ sectors. As a result, it is not clear whether the growth rate is more sensitive to a higher cost of capital in a model with endogenous transaction costs.

\section{Extensions}

In this section, we discuss several extensions of our basic framework endogenizing transaction costs of collusion. 


\subsection{Vertical Collusion between the Principal and the Supervisor}

In our model, there is so far no scope for any vertical collusion between the principal and the supervisor or the agent. The reason is simple: when the principal can fully commit to the rewards given to the supervisor, he already offers what is best from his own point of view. To give to the principal a more active role and to open the possibility for some vertical collusion with the supervisor, we relax the commitment assumption.

If the principal cannot commit to reward the supervisor for taking the right decision, rewards and reports must also be self-enforceable and this may put constraints on the outputs that can be implemented. The firm is now viewed as a nexus of implicit relationships between the principal and the supervisor on the one side, and between the supervisor and the management on the other side.

To offer the simplest analysis of these new considerations, we will depart from our previous assumption that the productivity shock $\theta$ is privately observed by the supervisor and the manager only. For the purpose of this section, we will thus assume that $\theta$ is also observable by the principal but that this piece of information remains non-verifiable when $\bar{\theta}$ realizes. The non-verifiability of this state of nature poses a similar problem to what we have analyzed with asymmetric information when $\bar{\theta}$ could be manipulated by the supervisor. In both cases, the outputs and wages cannot be specified as functions of the state of nature $\theta$. In such contexts, and even though they may be suboptimal, incentive contracts are particularly interesting tools to consider. ${ }^{29}$ Incentive contracts are again triplets of the form $\left\{x_{t+\tau}(\hat{\theta}), s_{t+\tau}(\hat{\theta}), T_{t+\tau}(\hat{\theta})\right\}_{\hat{\theta} \in S}$, exactly as under asymmetric information. ${ }^{30}$

The principal is supposed not to have time and expertise to select what should be the production plan and wage in each state of nature. Instead, the principal has to delegate this task to the supervisor and offers him a contract to do so. Given that state $\bar{\theta}$ is the only state which cannot be described in a contract, the supervisor's discretion lies now in his ability to choose between two possible options when $\bar{\theta}$ realizes. When $\underline{\theta}$ realizes, the supervisor has no discretion since this state of nature is fully verifiable. The contract, of course, has to induce the supervisor to do the right choice from the owners' point of view.

\footnotetext{
${ }^{29}$ We will assume that revelation mechanisms à la Maskin (1999) to elicit this commonly known piece of information are not available : a standard assumption in the incomplete contract literature. This can be justified if there exist communication costs precluding to open communication channels between a benevolent third-party (court of law) offering this mechanism and either the principal or the agent.

${ }^{30}$ See Laffont and Martimort (2002, Chapter 6) for a discussion of the role of incentive contracts when the commonly observed the state of nature is non-verifiable.
} 
If it does not do so, the supervisor can instead choose to please the manager and share with him the rent obtained, had the supervisor chosen the contract corresponding to state $\underline{\theta}$ when, instead, $\bar{\theta}$ realizes. Obviously, the fact that the state of nature is observable by the principal allows him to check whether the supervisor has complied or not at any given date and to punish accordingly in the continuation of their relationship if a deviation has been observed. ${ }^{31}$ Clearly, what the possible vertical collusion between the principal and the supervisor aims at doing is to solve this moral hazard problem in supervision.

As before, we will assume that the principal offers a stationary contract such that $s_{t+\tau}(\bar{\theta})=s_{t}(\bar{\theta})(1+g)^{\frac{\tau \alpha}{\alpha-1}}\left(\right.$ resp. $\left.s_{t}(\underline{\theta})=0\right)$ and $x_{t+\tau}(\theta)=x_{t}(\theta)(1+g)^{\frac{\tau}{\alpha-1}}$.

However, we now leave open the possibility that the owners may renege from the wage promised to the supervisor if they find optimal to do so. We are interested in describing a subgame-perfect coalition-proof equilibrium of this game. ${ }^{32}$ In such an equilibrium, owners continue to reward the supervisor because they expect him to always take the right decision. Reciprocally, the supervisor continues to choose the correct option in the menu proposed by the principal because he expects owners to stick to the promised rewards. If owners were to deviate at a given date, the supervisor and the agent would move to a collusive self-enforcing agreement from the next date on.

Let us now describe precisely the strategies of all players in the subgame-perfect coalition-proof equilibrium.

- Owners : They pay $s_{t+\tau}(\bar{\theta})=\delta U_{t+\tau}(\bar{\theta})$ to the supervisor at each date $t+\tau$ where $\bar{\theta}$ realizes if the supervisor chooses $\left\{x_{t+\tau}(\bar{\theta}), T_{t+\tau}(\bar{\theta})\right\}$ within the menu proposed. If there is a single date $t+\tau$ at which the supervisor chooses $\left\{x_{t+\tau}(\underline{\theta}), T_{t+\tau}(\underline{\theta})\right\}$ when $\bar{\theta}$ realizes, owners stop paying him at all future dates $t+\tau^{\prime}>t+\tau$.

- Supervisor : He chooses $\left\{x_{t+\tau}(\bar{\theta}), T_{t+\tau}(\bar{\theta})\right\}$ within the menu proposed when $\bar{\theta}$ realizes at date $t+\tau$ (he chooses $\left\{x_{t+\tau}(\underline{\theta}), T_{t+\tau}(\underline{\theta})\right\}$ otherwise) as long as he has received a wage $s_{t+\tau},(\bar{\theta}) \geq \delta U_{t+\tau},(\bar{\theta})$ at all dates $t+\tau^{\prime}>t+\tau$. If there is a single date $t+\tau^{\prime}$ where $s_{t+\tau^{\prime}}(\bar{\theta})<\delta U_{t+\tau^{\prime}}(\bar{\theta})$, the supervisor chooses $\left\{x_{t+\tau}(\underline{\theta}), T_{t+\tau}(\underline{\theta})\right\}$ when $\bar{\theta}$ realizes from this date on and gets a bribe from the $\bar{\theta}$ management.

\footnotetext{
${ }^{31}$ The fact that the state of nature is observed even though it is not always verifiable is important to make easier the detection of a deviation by the supervisor. This does not mean that the insights we will get below do not carry over in a model where the principal remains uninformed on the exact shock $\theta$ as we know from the general literature on repeated game with imperfect public information (see Fudenberg, Levine and Maskin (1994)). However, assuming observability makes the analysis easier.

${ }^{32}$ See Bernheim, Peleg and Whinston (1987) for a formal definition.
} 
- Manager : Following the owners' deviation and as long as the supervisor has chosen $\left\{x_{t+\tau}(\underline{\theta}), T_{t+\tau}(\underline{\theta})\right\}$ at date $t+\tau$ when $\bar{\theta}$ realizes, then the agent bribes him $b_{t+\tau}$. If there is a single date $t+\tau_{0}$ at which the supervisor further deviates from this collusive continuation with the manager and reports the truth to the owners, the management stops bribing from date $t+\tau_{0}$ on.

In the Appendix, we check that those strategies form a subgame-perfect coalitionproof equilibrium. Let us write the corresponding incentive compatibility constraint for the owners. Given the supervisor's strategy, behaving yields to the owners the following intertemporal expected payoff :

$$
V_{t}=\sum_{\tau=0}^{\infty}\left(\frac{1-\lambda E}{1+r}\right)^{\tau}\left\{\nu\left(T_{t+\tau}(\bar{\theta})-\delta \bar{A}_{t} \Delta \theta x_{t+\tau}^{\alpha}(\underline{\theta})\right)+(1-\nu) T_{t+\tau}(\underline{\theta})\right\},
$$

where the dividends $T_{t+\tau}(\theta)$ is given by (19).

By deviating at date $t$ and not rewarding the supervisor for his choice, owners get instead :

$$
\nu T_{t}(\bar{\theta})+(1-\nu) T_{t}(\underline{\theta})+\sum_{\tau=1}^{\infty}\left(\frac{1-\lambda E}{1+r}\right)^{\tau} T_{t+\tau}(\underline{\theta}) .
$$

Hence, the owners' incentive constraint becomes :

$$
\sum_{\tau=1}^{\infty}\left(\frac{1-\lambda E}{1+r}\right)^{\tau}\left(T_{t+\tau}(\bar{\theta})-T_{t+\tau}(\underline{\theta})\right) \geq \sum_{\tau=0}^{\infty}\left(\frac{1-\lambda E}{1+r}\right)^{\tau} \delta \bar{A}_{t} \Delta \theta x_{t+\tau}^{\alpha}(\underline{\theta}) .
$$

Taking into account (19) to express the dividends as functions of outputs and assuming the owners offer a stationary contract such that $x_{t+\tau}(\theta)=x_{t}(\theta)(1+g)^{\frac{\tau}{\alpha-1}}$, this latter inequality becomes :

$$
\bar{\theta} x_{t}^{\alpha}(\bar{\theta})-\omega x_{t}(\bar{\theta})-\left(\underline{\theta} x_{t}^{\alpha}(\underline{\theta})-\omega x_{t}(\underline{\theta})\right) \geq \Delta \theta x_{t}^{\alpha}(\underline{\theta}) .
$$

This is essentially a static constraint where the discount factor has disappeared. It obviously holds by definition of $x_{t}^{\alpha}(\bar{\theta})$ if we take the full commitment outputs found in the previous sections $x_{t}(\bar{\theta})=\omega^{\frac{1}{\alpha-1}} \bar{\theta}^{\frac{1}{1-\alpha}}$ and $x_{t}(\underline{\theta})=\omega^{\frac{1}{\alpha-1}} \tilde{\theta}(\delta(E))^{\frac{1}{1-\alpha}}$.

Henceforth, we can conclude :

Proposition 5 The optimal contract with full commitment and adverse selection can still be implemented as a subgame perfect coalition-proof equilibrium when the owners cannot commit to the supervisor's reward but observe productivity shocks. All our previous results are thus unchanged. 
Even though the lack of commitment on the owners' side in a model with observability of the state of nature opens a priori some scope for more inefficiency, the incentive constraint (29) turns out to be always satisfied by the full commitment solution obtained with incentive contracts. With a vertical collusion, profits are thus the same as under full commitment and asymmetric information. Consequently, the growth rate of the economy remains the same.

It should be stressed that the endogeneity of transaction costs is key to our results. Because the supervisor's wage is the manager's rent discounted by a factor $\delta$, the owners' gain from deviating at a given date and stopping rewarding the supervisor has the same magnitude as the cost of this deviation which is precisely the discounted difference between the dividends received from the two types of managers from that date on. Hence, (29) becomes essentially a static incentive constraint which is trivially satisfied.

Proposition 5 shows also that the vertical collusion between the principal and the supervisor is the glue which compensates the lack of commitment but it has no impact on the growth rate of the economy since the owners' incentive constraint is slack. The real constraint in the economy comes from the existing collusion between supervision and management. This justifies also our focus on horizontal collusion in the first place as the most relevant incentive problem in the organization.

This stands in sharp contrast with a recent paper, written after the first version of this work was completed, by François and Roberts (2000). These authors focus instead on a pure moral hazard problem in a repeated contracting environment involving only a principal and a single agent. The vertical collusion between the two may help to overcome this moral hazard problem at a cost. The main point of the paper is that growth, by shortening the horizon of those implicit relationships, has a detrimental impact on effort within the firm. Our results above suggest that issues related to vertical collusion may be less important when compared to other agency problems between agents of the organization. In that case, the conclusion is reversed: growth, by shortening implicit relationships which are detrimental to the firm, has a positive effect on incentives within the firm.

\subsection{Information Structure}

Let us now allows owners to verify the supervisor's report $\underline{\theta}$ at date $t+\tau$ with probability $\varepsilon$. For instance, changes in communication technologies, use of external auditing firms 
which do not collude with the management and, sometimes, better comparisons of the firm's performances with those of related firms in other sectors of the economy may help the principal to reduce the scope for information manipulations by the supervisor. ${ }^{33}$

This random audit has of course a direct effect on the coalition incentive constraint which is now relaxed. To see that, let us rewrite the supervisor and the manager's incentive constraint in $\Gamma_{t}$ given that they follow the same strategies as in Section 6 . The supervisor prefers hiding $\bar{\theta}$ to the principal as long as :

$$
\sum_{\tau=0}^{\infty}\left(\frac{1-\lambda E}{1+r}\right)^{\tau} s_{t+\tau} \leq(1-\varepsilon)\left(\sum_{\tau=0}^{\infty}\left(\frac{1-\lambda E}{1+r}\right)^{\tau} b_{t+\tau}\right) .
$$

The manager behaves and bribes the supervisor when :

$$
(1-\varepsilon)\left(\sum_{\tau=0}^{\infty}\left(\frac{1-\lambda E}{1+r}\right)^{\tau}\left(U_{t+\tau}(\bar{\theta})-b_{t+\tau}\right)\right) \geq(1-\varepsilon) U_{t}(\bar{\theta}) .
$$

Gathering those two equations, the coalition-incentive compatibility constraint rewrites as :

$$
\sum_{\tau=0}^{\infty}\left(\frac{1-\lambda E}{1+r}\right)^{\tau} s_{t+\tau}(\bar{\theta}) \geq(1-\varepsilon)\left(\sum_{\tau=1}^{\infty}\left(\frac{1-\lambda E}{1+r}\right)^{\tau} U_{t+\tau}(\bar{\theta})\right)
$$

For a stationary contract such that $s_{t+\tau}(\bar{\theta})=s_{t}(\bar{\theta})(1+g)^{\frac{\tau \alpha}{\alpha-1}}$ and $x_{t+\tau}(\theta)=x_{t}(\theta)(1+$ $g)^{\frac{\tau}{\alpha-1}}$, this coalition-incentive constraint becomes :

$$
s_{t}(\bar{\theta}) \geq(1-\varepsilon) \delta(E) U_{t}(\bar{\theta})
$$

Clearly, (30) shows that the coalition-incentive constraint becomes less sensitive to the variations in the growth rate. The multiplier effect found above is thus reduced. As a result, improvements in control technologies reduce agency costs and improve the growth rate of the economy.

\subsection{Building-Up Horizontal Trust between the Supervisor and the Agent}

In his celebrated book The Rise and Decline of Nations Olson (1982, p.42) has forcefully argued, that "Stable Societies with unchanged boundaries tend to accumulate more

\footnotetext{
${ }^{33}$ To be valid, the yardstick competition argument here assumes implicitly that shocks in all sectors are no longer i.i.d. but correlated. This would require to change slightly the modeling.
} 
collusions and organizations for collective action over time". Starting from this casual observation, Olson describes a dynamics of the economy which emphasizes that collusion has detrimental consequences for growth and ends up justifying some form of sclerosis for societies as a whole.

To model the accumulation of trust and (collusive) social capital within the firm, let us suppose that the supervisor and the agent faces a different cost of transferring bribes in the first period of their collusive relationship and thereafter. For a self-enforcing collusive agreement starting at date $t$, transferring a first bribe $b_{t} \operatorname{costs}(1+\mu) b_{t}$ to the agent whereas transferring bribe $b_{t+\tau}$ at future dates $(\tau \geq 1)$ costs only $b_{t+\tau}$ where $\mu>0$. This simple modeling captures the fact that collusion becomes easier when it has already occurred in the past. We model therefore a situation where collusive partners build the conditions for a better collusive relationship in the future if early on they stick to the collusive agreement.

To simplify the analysis of the game $\Gamma_{t}$ played by the supervisor and the manager, we will focus on the case where they exchange stationary bribes $b_{t+\tau}=b_{t}(1+g)^{\frac{\tau \alpha}{\alpha-1}}$ at each date.

In this framework, the manager sticks to the collusive strategy at date $t$ when :

$$
\sum_{\tau=0}^{\infty}\left(\frac{1-\lambda E}{1+r}\right)^{\tau}\left(U_{t+\tau}(\bar{\theta})-b_{t+\tau}\right) \geq U_{t}(\bar{\theta})+\mu b_{t}
$$

where $\mu b_{t}$ can be viewed as the extra gain from not bribing the supervisor today.

Taking into account the stationary of the contract and the bribes, this inequality can be rewritten as :

$$
\frac{\delta(E)}{1+\mu(1-\delta(E))} U_{t}(\bar{\theta}) \geq b_{t}
$$

Still, the supervisor does not deviate from the collusive equilibrium at date $t$ when :

$$
\sum_{\tau=0}^{\infty}\left(\frac{1-\lambda E}{1+r}\right)^{\tau} s_{t+\tau}(\bar{\theta}) \leq \sum_{\tau=0}^{\infty}\left(\frac{1-\lambda E}{1+r}\right)^{\tau} b_{t+\tau}
$$

or, using again stationarity

$$
s_{t}(\bar{\theta}) \leq b_{t}
$$

Gathering equations (31) and (32), we find that the coalition-incentive compatibility 
constraint writes now as ${ }^{34}$ :

$$
s_{t}(\bar{\theta}) \geq k(\delta(E)) U_{t}(\bar{\theta})
$$

where $k(\delta)=\frac{\delta}{1+\mu(1-\delta)}$ is an increasing and convex function of $\delta$ such that $k(\delta) \leq \delta$ for all $\delta \in[0,1]$.

The fact that $k(\cdot)$ is convex makes the efficiency of collusion be very sensitive to small changes in the growth rate and thus changes in $\delta(E)$. As a result it may be that the research equation (10) becomes upward slopping over some range of values of $E$. This non-monotonicity creates scope for multiple equilibria.

Proposition 6 There exists values of the parameters $L, \Delta \theta, \nu, \alpha, r$ and $\mu$ such that there exist multiple equilibria.

Without trust accumulation in the relationship, the efficiency of side-contracting is exactly the true discount factor faced by all agents in society (namely $\delta(E)$ ). The collusive partners are no more eager than owners to see their relationship lasting longer. When collusive exchanges are easier over time, the efficiency of side-contracting is a convex function of the discount $\delta(E)$. A small increase in the growth rate may thus trigger a significative increase in the transaction costs of side-contracting making thus the research equation upward slopping over some range. This in turn creates some scope for the existence of multiple equilibria in growth and collusion.

Typically, with multiple equilibria, economies with very similar parameter values may end up in quite different patterns. Some may experience low growth, long-lasting implicit relationships with rather low transaction costs of side-contracting. Others, on the contrary, may end up with more growth, shorter social relationships with large transaction costs to implement collusion. The first type of economies corresponds to more bureaucratized societies than the second one.

\section{Conclusion}

Let us first recast the main argument of our paper. In our model, the macroeconomic environment and the microeconomic conditions strongly interact to determine the equilibrium growth rate. A higher rate of creative destruction decreases the expected life of

\footnotetext{
${ }^{34}$ Note that it is easier for the owners to induce a deviation from the collusive equilibrium starting at date $t$ at this date rather than inducing such a deviation at a date $t+\tau$ since the latte would require to offer a wage $s_{t}(\bar{\theta}) \geq \delta(E) U_{t}(\bar{\theta})$, i.e., a higher wage than what is required by $(33)$.
} 
agents within organizations. It therefore decreases their ability to collude efficiently and to undermine the firm's average profitability. This, in turn, increases the incentives of the $R \& D$ sectors to innovate. The growth rate of the economy is thus shown to be highly dependent on the dynamics of collusive relationships within the firm. Social relationships on the work place and the growth process are thus strongly intertwined.

Several extensions of our basic model would be worth pursuing. First, agency costs in the final sectors could be introduced. The results obtained above would be robust to such an extension. Indeed, suppose that there is asymmetric information in the final sectors where firms are now characterized by a separation between ownership and control. Reducing the rent of agents within these firms calls for decreasing the demand for input exactly as in our model the supply of output of the intermediate sectors was reduced. Again, this reduces the incentives of the $\mathrm{R} \& \mathrm{D}$ sectors because being an intermediate monopolist becomes less valuable. The drawback of such a model is that it loses what we think is a crucial point of our paper: the feed-back effect of growth on agency costs. Indeed, since firms in the final sectors are infinitely lived, the transaction costs of sidecontracting would be independent of the growth process.

Second, agency costs could also be added in the $\mathrm{R} \& \mathrm{D}$ sectors with other research technologies than what we have chosen above. Note that those firms are typically managed by their owners so that the most important source of agency costs comes from their difficult access to the capital market. The existence of those agency costs would clearly makes more costly innovation and this creates a brake to the growth process. Again, what is less clear is whether the growth process affects directly these agency costs. ${ }^{35}$ It seems to us that the interesting feed-back from the growth process to agency costs can only be obtained in considering firms which produce on large scale and have already evolved towards a rather complex organizational structure.

Third, monopolists in the intermediate sectors are supposed to be rather passive in our framework. They do not undertake any research to keep their monopoly position. ${ }^{36}$ If such an extension was considered, the allocation of resources between innovation and production of the current vintage technology could also be subject to collusive behavior within the firm. We plan to investigate some of these extensions in future research.

\footnotetext{
${ }^{35}$ Of course, it does so indirectly through the impact on the interest rate in a model with capital accumulation. Note that, in our model as in Aghion and Howitt (1992)'s original model, this interest rate is fixed.

${ }^{36}$ See Stein (1997) for such a model.
} 


\section{REFERENCES}

Acemoglu, D. and F. Zilibotti, 1999, "Information Accumulation in Economic Development," Journal of Economic Growth, 4: 5-38.

Aghion, P., M. Dewatripont and P. Rey, 1999, "Competition, Financial Discipline and Growth," Review of Economic Studies, 66: 825-853.

Aghion, P. and P. Howitt, 1992, "A Model of Growth Through Creative Destruction," Econometrica, 62: 257-282.

Aghion, P. and P. Howitt, 1998, Endogenous Growth Theory, MIT Press, Cambridge.

Bernheim, B., D. Peleg and M. Whinston, 1987, "Coalition-Proof Nash Equilibria: Concepts," Journal of Economic Theory, 42: 1-12.

Crozier, M., 1962, Le Phénomène Bureaucratique, Editions du Seuil, Paris.

Dalton, M., 1959, Men who Manage, Wiley and Sons, New-York.

Faure-Grimaud, A. , J.J. Laffont and D. Martimort, 2001, "Collusion, Delegation and Supervision with Soft Information," forthcoming Review of Economic Studies.

Fudenberg, D., D. Levine and E. Maskin, 1994, "The Folk Theorem with Imperfect Public Information," Econometrica, 62: 997-1039.

Franois, P. and J. Roberts, 2000, "Contracting Productivity Growth," mimeo Center, Tilburg.

Granovetter, M., 1992, "The Sociological and Economic Approaches to labor Market Analysis: A Social Structural View" in Granovetter M. and R. Swedberg, eds. The Sociology of Economic Life, Westview Press, New-York.

Grossman, G. and E. Helpman, 1992, Innovation and Growth in the Global Economy, MIT Press, Cambridge.

Laffont, J.J. and D. Martimort, 2002, The Theory of Incentives: The Principal-Agent Model, Princeton University press.

Levin, J., 2000, "Relational Incentive Contracts," mimeo Stanford University. 
Martimort, D., 1999, "The Life Cycle of Regulatory Agencies: Dynamic Capture and Transaction Costs," Review of Economic Studies, 66: 929-948.

Martimort, D. and T. Verdier, 2000, "The Internal Organization of the Firm, Transaction Costs and Macroeconomic Growth," Journal of Economic Growth, 5,4, 315340.

Maskin, E., 1999, "Nash Equilibrium and Welfare Optimality," Review of Economic Studies, 66: 23-38.

Myerson, R., 1979, "Incentive Compatibility and the Bargaining Problem," Econometrica, 47: 61-73.

Olson, M., 1982, The Rise and Decline of Nations: Economic Growth, Stagflation, and Social Rigidities, Harvard University Press, Cambridge.

Pfeffer, J., 1981, Power In Organizations, Ballinger Publishing Compagny, Cambridge, MA.

Stein, J., 1997, "Waves of Creative Destruction: Firm-Specific Learning-by-Doing and the Dynamics of Innovation," Review-of-Economic-Studies, 64: 265-88.

Thesmar, D. and M. Thoenig, 2000, "Creative Destruction and Firm Organization Choice," Quarterly Journal of Economics, 115: 1201-1237.

Tirole, J., 1986, "Hierarchies and Bureaucracies: On the Role of Collusion in Organizations," Journal of Law, Economic and Organization, 2: 181-214.

Tirole, J., 1992, "Collusion and the Theory of Organizations," in Advances in Economic Theory, vol. 2, ed. J.J. Laffont, 151-206, Cambridge University Press. 


\section{Appendices}

\section{- Proof of Proposition 4}

Define $u=1-\delta \in[0,1]$. Because $\delta^{\prime}(E)<0$, we have $u^{\prime}(E)>0$. Then, under the approximation that $r$ and $\lambda E$ are small enough, (9) rewrites as a function of $u$

$$
\omega_{1}^{\frac{1}{1-\alpha}-\gamma}(u)=\lambda(1-\alpha) \alpha^{\frac{\alpha}{1-\alpha}} \frac{1}{u}\left(\nu \bar{\theta}^{\frac{1}{1-\alpha}}+(1-\nu)\left(\underline{\theta}-\frac{\nu}{1-\nu}(1-u) \Delta \theta\right)^{\frac{1}{1-\alpha}}\right) .
$$

Denoting $\underline{\tilde{\theta}}(u)=\underline{\theta}-\frac{\nu}{1-\nu}(1-u) \Delta \theta$, we have :

$$
\begin{aligned}
\left(\frac{1}{1-\alpha}-\gamma\right) \frac{d \omega_{1}}{\omega_{1} d u} & =-\frac{1}{u}+\frac{\nu \Delta \theta}{(1-\alpha)} \frac{\tilde{\theta}(u)^{\frac{\alpha}{1-\alpha}}}{\tilde{\Theta}(u)^{\frac{1}{1-\alpha}}} \\
& =-\frac{\tilde{\theta}(u)^{\frac{\alpha}{1-\alpha}}}{\tilde{\Theta}(u)^{\frac{1}{1-\alpha}} u}\left[\nu \bar{\theta}^{\frac{1}{1-\alpha}} \tilde{\theta}(u)^{-\frac{\alpha}{1-\alpha}}+(1-\nu) \underline{\tilde{\theta}}(u)-\frac{\nu}{1-\alpha} u \Delta \theta\right] \\
& =-\frac{\tilde{\theta}(u)^{\frac{\alpha}{1-\alpha}}}{u \tilde{\Theta}(u)^{\frac{1}{1-\alpha}}}\left[\nu \bar{\theta}^{\frac{1}{1-\alpha}} \tilde{\theta}(u)^{-\frac{\alpha}{1-\alpha}}+(1-\nu) \underline{\theta}-\nu \Delta \theta\left(1-u+\frac{u}{1-\alpha}\right)\right]
\end{aligned}
$$

Let us denote by $\phi(u)$ the bracketed term above. We observe that

$$
\phi^{\prime}(u)=-\frac{\alpha \nu}{1-\alpha} \Delta \theta\left(1+\frac{\nu}{1-\nu}\left(\frac{\bar{\theta}}{\underline{\tilde{\theta}}(u)}\right)^{\frac{1}{1-\alpha}}\right)<0 .
$$

Moreover, we have $\phi(1)=\nu \bar{\theta}^{\frac{1}{1-\alpha}} \underline{\theta}^{-\frac{\alpha}{1-\alpha}}+(1-\nu) \underline{\theta}-\frac{\nu \Delta \theta}{1-\alpha}$. Let us view $\phi(1)$ as a function of $\Delta \theta$, keeping $\underline{\theta}$ fixed. We have $\frac{\partial \phi}{\partial \Delta \theta}(1, \Delta \theta)=\frac{\nu}{1-\alpha}\left[\left(\frac{\bar{\theta}}{\underline{\theta}}\right)^{\frac{\alpha}{1-\alpha}}-1\right]>0$ and $\phi(1,0)=\underline{\theta}>0$. Hence $\phi(1, \Delta \theta)>0$ for all $\Delta \theta>0$. Therefore, $\phi(u)>0 \forall u \in[0,1]$ and $\frac{d \omega_{1}}{d u}<0$.

Let us define by $\omega_{1}(E, k)$ the research arbitrage equation when the efficiency of sidecontracting $k$ is fixed.

We observe that $\omega_{1}\left(0, \frac{1}{1+r}\right)=\tilde{\omega}_{1}(0)$ and since

$$
\begin{aligned}
& \left(\frac{1}{1-\alpha}-\gamma\right) \frac{1}{\tilde{w}_{1}(E)} \frac{d \tilde{\omega}_{1}}{d E}(E)= \\
& \left(\frac{1}{1-\alpha}-\gamma\right) \frac{1}{\omega_{1}\left(E, \frac{1}{1+r}\right)} \frac{d \omega_{1}}{d E}\left(E, \frac{1}{1+r}\right)+\frac{\nu \Delta \theta}{1-\alpha} \frac{\tilde{\theta}(E)^{\frac{\alpha}{1-\alpha}}}{\tilde{\Theta}(E)^{\frac{1}{1-\alpha}}} \frac{d u}{d E}
\end{aligned}
$$

We have $\frac{1}{\tilde{\omega}_{1}} \frac{d \tilde{\omega}_{1}}{d E}>\frac{1}{\omega_{1}} \frac{d \omega_{1}}{d E}, \forall E$. 
Integrating between 0 and $E$ yields $\log \left(\frac{\tilde{\omega}_{1}(E)}{\tilde{\omega}_{1}(0)}\right)>\log \left(\frac{\omega_{1}\left(E, \frac{1}{1+r}\right)}{\omega_{1}\left(0, \frac{1}{1+r}\right)}\right)$ so that $\tilde{\omega}_{1}(E)>\omega_{1}\left(E, \frac{1}{1+r}\right), \forall E>0$. The research arbitrage equation (9) is shifted upwards when there are endogenous transaction costs of collusion. Leading to $\omega^{*}>\omega\left(\frac{1}{1+r}\right)$ and $E^{*}>E\left(\frac{1}{1+r}\right)$.

\section{- Vertical Collusion between the Principal and the Supervisor :}

We check there that the proposed strategies form a subgame-perfect coalition-proof equilibrium.

Suppose that the principal has deviated at date $t$ and offered less than $\delta(t) U_{t+\tau}(\bar{\theta})$ (the argument is the same for a deviation at date $t+\tau(\tau>0)$ because of the stationarity of the contract). Then, the supervisor prefers colluding from date $t+1$ on with the agent rather than deviating and getting zero (from the owners' strategy) when :

$$
b_{t+1}+\sum_{\tau=1}^{\infty}\left(\frac{1-\lambda E}{1+r}\right)^{\tau} b_{t+\tau+1} \geq 0 .
$$

In turn, the management does not deviate as long as :

$$
U_{t+1}(\bar{\theta})-b_{t+1}+\sum_{\tau=1}^{\infty}\left(\frac{1-\lambda E}{1+r}\right)^{\tau}\left(U_{t+\tau+1}(\bar{\theta})-b_{t+\tau+1}\right) \geq U_{t+1}(\bar{\theta}) .
$$

Clearly, constraints (A1) and (A2) holds for a stationary contract when :

$$
\frac{\delta(E)}{1-\delta(E)} U_{t+1}(\bar{\theta}) \geq \sum_{\tau=1}^{\infty}\left(\frac{1-\lambda E}{1+r}\right)^{\tau} b_{t+\tau+1} \geq 0
$$

Clearly, a bribe $b_{t+\tau+1}=b_{t+1}(1+g)^{\frac{\tau \alpha}{\alpha-1}}$ where $b_{t+1}=U_{t+1}(\bar{\theta})-\varepsilon$ satisfies (A3).

Suppose that the principal has not deviated at date $t$ and that the supervisor contemplates the benefit from a deviation, i.e., accepting bribes from that date on. The supervisor does not deviate when :

$$
\sum_{\tau=0}^{\infty}\left(\frac{1-\lambda E}{1+r}\right)^{\tau} s_{t+\tau}(\bar{\theta}) \geq \sum_{\tau=0}^{\infty}\left(\frac{1-\lambda E}{1+r}\right)^{\tau} b_{t+\tau}
$$

Moreover, the bribes $\left\{b_{t+\tau}\right\}_{\tau \geq 0}$ must be self-enforceable and thus satisfy the agent's incentive constraint, i.e.,

$$
\sum_{\tau=0}^{\infty}\left(\frac{1-\lambda E}{1+r}\right)^{\tau}\left(U_{t+\tau}(\bar{\theta})-b_{t+\tau}\right) \geq U_{t}(\bar{\theta})
$$


which gives for a stationary contract

$$
\sum_{\tau=0}^{\infty}\left(\frac{1-\lambda E}{1+r}\right)^{\tau} b_{t+\tau} \leq \frac{\delta(E)}{1-\delta(E)} U_{t}(\bar{\theta}) .
$$

There is no scope for a self-enforceable deviation by the supervisor when :

$$
\sum_{\tau=0}^{\infty}\left(\frac{1-\lambda E}{1+r}\right)^{\tau} s_{t+\tau}(\bar{\theta}) \geq \frac{\delta(E)}{1-\delta(E)} U_{t}(\bar{\theta})
$$

which gives for a stationary contract

$$
s_{t}(\bar{\theta}) \geq \delta(E) U_{t}(\bar{\theta})
$$

\section{- Proof of Proposition 6}

The proof proceeds as that of Proposition 4 and we use the same notations $(u=1-\delta)$. We note that (9) rewrites as :

$$
w_{1}^{\frac{1}{1-\alpha}-\gamma}(u)=\lambda(1-\alpha) \alpha^{\frac{\alpha}{1-\alpha}} \frac{1}{u}\left(\nu \bar{\theta}^{\frac{1}{1-\alpha}}+(1-\nu)\left(\underline{\theta}-\frac{v}{1-\nu} k(1-u) \Delta \theta\right)^{\frac{1}{1-\alpha}}\right) .
$$

with $k(1-u)=\frac{1-u}{1+\mu-\mu(1-u)}$ Denoting now $\underline{\tilde{\theta}}(u)=\underline{\theta}-\frac{\nu}{1-\nu} k(1-u) \Delta \theta$, we have :

$$
\begin{aligned}
& \left(\frac{1}{1-\alpha}-\gamma\right) \frac{d \omega_{1}}{\omega_{1} d u}=-\frac{1}{u}+\frac{\nu \Delta \theta}{1-\alpha} k^{\prime}(1-u) \frac{\tilde{\theta}(u)^{\frac{\alpha}{1-\alpha}}}{\tilde{\Theta}(u)^{\frac{1}{1-\alpha}}} \\
= & -\frac{\tilde{\theta}(u)^{\frac{\alpha}{1-\alpha}}}{u \tilde{\Theta} \frac{1}{1-\alpha}(u)}\left[\nu \bar{\theta}^{\frac{1}{1-\alpha}} \underline{\tilde{\theta}}(u)^{-\frac{\alpha}{1-\alpha}}+(1-\nu) \underline{\theta}-\nu \Delta \theta\left(k(1-u)+\frac{u k^{\prime}(1-u)}{1-\alpha}\right)\right] .
\end{aligned}
$$

Denoting by $\phi(u)$ the bracketed term, we observe that :

$$
\phi^{\prime}(u)=\nu k^{\prime}(1-u) \Delta \theta\left[\frac{2 \mu u}{1+\mu u} \frac{1}{1-\alpha}-\frac{\alpha}{1-\alpha}\left(1+\frac{\nu}{1-\nu}\left(\frac{\bar{\theta}}{\underline{\tilde{\theta}}(u)}\right)^{\frac{1}{1-\alpha}}\right)\right] .
$$

Note that $\delta$ describes almost all $\left[0, \frac{1}{1+r}\right]$ and thus $u$ describes almost all $\left[\frac{r}{1+r}, 1\right]$ also. Observe then that the first term in the bracketed term above is strictly increasing in $u$ whereas the second is strictly decreasing.

There exists a unique value $u^{*}>\frac{r}{1+r}$ such that $\phi^{\prime}\left(u^{*}\right)=0\left(\right.$ inflexion point of $\left.\omega_{1}(u)\right)$ when :

$$
\frac{2 \mu r}{1+r+\mu r}<\alpha\left(1+\frac{\nu}{1-\nu}\left(\frac{\bar{\theta}}{\underline{\theta}-\frac{\nu}{(1-\nu)} \frac{\Delta \theta}{1+\mu r+r}}\right)^{\frac{1}{1-\alpha}}\right)
$$


which holds for $r$ small enough.

Then, $u^{*}$ is given by

$$
\frac{2 \mu u^{*}}{1+\mu u^{*}}=\alpha\left(1+\frac{\nu}{1-\nu}\left(\frac{\bar{\theta}}{\underline{\tilde{\theta}}\left(u^{*}\right)}\right)^{\frac{1}{1-\alpha}}\right) .
$$

We can then compute $\phi\left(u^{*}\right)$ as :

$$
\begin{aligned}
\phi\left(u^{*}\right) & =(1-\nu) \underline{\tilde{\theta}}\left(u^{*}\right)\left[1+\frac{\nu}{1-\nu}\left(\frac{\bar{\theta}}{\tilde{\tilde{\theta}}\left(u^{*}\right)}\right)^{\frac{1}{1-\alpha}}\right]-\frac{\nu}{(1-\alpha)} \frac{u^{*}(1+\mu)}{\left(1+\mu u^{*}\right)^{2}} \Delta \theta \\
& =\frac{2 \mu(1-\nu) u^{*}}{\alpha\left(1+\mu u^{*}\right)}\left[\underline{\tilde{\theta}}\left(u^{*}\right)-\frac{\nu \alpha(1+\mu) \Delta \theta}{(1-\nu)(1-\alpha)\left(1+\mu u^{*}\right) 2 \mu}\right] .
\end{aligned}
$$

Note that $\phi(0)=\nu \bar{\theta}^{\frac{1}{1-\alpha}} \underline{\tilde{\theta}}^{-\frac{\alpha}{1-\alpha}}+(1-\nu) \underline{\theta}-\nu \Delta \theta>0$ (by definition since $\underline{\tilde{\theta}}=\underline{\theta}-\frac{\nu}{1-\nu} \Delta \theta>$ $0)$. Also, $\phi(1)=\nu \bar{\theta}^{\frac{1}{1-\alpha}} \underline{\theta}^{\frac{-\alpha}{1-\alpha}}+(1-\nu) \underline{\theta}-\frac{\nu \Delta \theta}{(1-\alpha)(1+\mu)}$ which is positive for $\mu$ large enough.

For $\mu$ large enough, $u^{*}$ can be approximated by $\frac{x}{\mu}$ where $x$ is a fixed number given by :

$$
\frac{2 x}{1+x}=\alpha\left(1+\frac{\nu}{1-\nu}\left(\frac{\bar{\theta}}{\underline{\theta}-\frac{\nu}{(1-\nu)} \frac{\Delta \theta}{1+x}}\right)^{\frac{1}{1-\alpha}}\right) .
$$

For $\mu$ large enough, we have $\phi\left(u^{*}\right)<0$ when

$$
\underline{\theta}-\frac{\nu \Delta \theta}{(1-\nu)(1+x)}<\frac{\nu \alpha \Delta \theta}{2(1-\nu)(1-\alpha)(1+x)} .
$$

Let us fix $\Delta \theta$ such that $\underline{\theta}$ is close to $\frac{\nu}{1-\nu} \Delta \theta$, then $x$ is given by :

$$
\frac{2 x}{1+x}=\alpha\left(1+\frac{\nu}{1-\nu}\left(\frac{1+x}{\nu x}\right)^{\frac{1}{1-\alpha}}\right) \text {, }
$$

and (A8) holds when :

$$
2 x<\frac{\alpha}{(1-\alpha)}
$$

Of course, there exists values of $\alpha$ and $\nu$ such that the solution to (A9) satisfies (A10). Take for instance $\nu$ close to zero, then $x \simeq \frac{\alpha}{2-\alpha}$ and (A10) holds for all $\alpha>0$.

Hence, we have proved that $\omega_{1}(u)$ may have an inflexion point with a positive derivative at this point. Now, by having $L$ having a medium range values $\omega_{2}(\cdot)$ may $\operatorname{cross} \omega_{1}(\cdot)$ more than once and multiple equilibria are shown to be possible. 